\title{
BMJ Open Determinants of continued maternal care seeking during pregnancy, birth and postnatal and associated neonatal survival outcomes in Kenya and Uganda: analysis of cross-sectional, demographic and health surveys data
}

\author{
Malachi Ochieng Arunda (D) , Anette Agardh, Benedict Oppong Asamoah
}

To cite: Arunda M0, Agardh A, Asamoah B0. Determinants of continued maternal care seeking during pregnancy, birth and postnatal and associated neonatal survival outcomes in Kenya and Uganda: analysis of crosssectional, demographic and health surveys data. BMJ Open 2021;11:e054136. doi:10.1136/ bmjopen-2021-054136

- Prepublication history and additional supplemental material for this paper are available online. To view these files, please visit the journal online (http://dx.doi.org/10.1136/ bmjopen-2021-054136).

Received 03 June 2021 Accepted 25 October 2021

Check for updates

(C) Author(s) (or their employer(s)) 2021. Re-use permitted under CC BY-NC. No commercial re-use. See rights and permissions. Published by BMJ.

Social Medicine and Global Health, Department of Clinical Sciences, Lund University, Malmö, Sweden

\section{Correspondence to} Malachi Ochieng Arunda; malachi.ochieng_arunda@med. lu.se

\section{ABSTRACT}

Objectives To examine how maternal and sociodemographic factors determine continued careseeking behaviour from pregnancy to postnatal period in Kenya and Uganda and to determine associated neonatal survival outcomes.

Design A population-based analysis of cross-sectional data using multinomial and binary logistic regressions.

Setting Countrywide, Kenya and Uganda.

Participants Most recent live births of 24502 mothers within 1-59 months prior to the 2014-2016 Demographic and Health Surveys.

Outcomes Care-seeking continuum and neonatal mortality.

Results Overall, $57 \%$ of the mothers had four or more antenatal care (ANC) contacts, of which $73 \%$ and $41 \%$ had facility births and postnatal care (PNC), respectively. Maternal/paternal education versus no education was associated with continued care seeking in majority of careseeking classes; relative risk ratios (RRRs) ranged from 2.1 to 8.0 (95\% Cl 1.1 to 16.3). Similarly, exposure to mass media was generally associated with continued care seekin; RRRs ranged from 1.8 to 3.2 (95\% $\mathrm{Cl} 1.2$ to 5.4). Care-seeking tendency reduced if a husband made major maternal careseeking decisions. Transportation problems and living in rural versus urban were largely associated with lower continued care use; RRR ranged from 0.4 to $0.7(95 \% \mathrm{Cl} 0.3$ to 0.9$)$. The two lowest care-seeking categories with no ANC and no PNC indicated the highest odds for neonatal mortality (adjusted OR 4.2, 95\% Cl 1.6 to 10.9). 23\% neonatal deaths were attributable to inadequate maternal care attendance. Conclusion Strategies such as mobile health specifically for promoting continued maternal care use up to postnatal could be integrated in the existing structures. Another strategy would be to develop and employ a brief standard questionnaire to determine a mother's continued careseeking level during the first ANC visit and to use the information to close the care-seeking gaps. Strengthening the community health workers system to be an integral part of promoting continued care seeking could enhance care seeking as a stand-alone strategy or as a component of aforementioned suggested strategies.

\section{STRENGTHS AND LIMITATIONS OF THIS STUDY}

$\Rightarrow$ The national representativeness of the data and the large sample size of the study allowed for valid stratified analysis with implications for national policy developments to improve neonatal survival outcomes for countries in the sub-Saharan Africa region.

$\Rightarrow$ Recall bias may not be completely eliminated from the study since the data were collected retrospectively through interviews.

$\Rightarrow$ However, by selecting the most recent births and owing to the fact that childbirth is a special event not easily forgettable, the study findings reflect the reality with considerable validity.

$\Rightarrow$ The study was based on maternal attendance to care and not the actual obstetric services received; thus, aspects related to lack of drugs, inadequate facilities or quality of care were not captured in our study.

\section{INTRODUCTION}

In 2019, close to 7000 newborns worldwide died within their first 28 days of life (neonatal period), as per the United Nations InterAgency Group for Child Mortality Estimation. ${ }^{1}$ Roughly three-quarters of these deaths occurred during childbirth and the first week of the neonatal period, ${ }^{12}$ and the major causes included infections such as sepsis and pneumonia, birth complications and prematurityrelated problems such as asphyxia and low birth weight. ${ }^{3}$ Comprehensive antenatal care (ANC), skilled birth attendance and postnatal (afterbirth) care (PNC) have long been recognised as key strategies that profoundly contribute to newborn survival. ${ }^{45}$ In 2015 , $64 \%$ of women globally had four or more ANC contacts, ${ }^{6}$ and prevalence of health facility births was $80 \%$ in $2019 .^{7}$ In high-income 
countries such as Sweden, where neonatal death rate is among the lowest globally (1.4 deaths per 1000 live births, in 2019), almost all mothers obtain comprehensive ANC, facility births and PNC services. ${ }^{8}$ However, in sub-Saharan African (SSA) and Southeast Asian countries, where over $70 \%$ of all neonatal deaths occur, ${ }^{9}$ use of the components of care is relatively low and varies substantially. ${ }^{10-12}$

Accordingly, since 2005, the WHO has been advocating for the implementation of continuum of care strategy, ${ }^{13}$ a concept that promotes continual access to care from prepregnancy to the first few weeks of after childbirth. ${ }^{13} 14$ While several SSA countries including Kenya and Uganda report over $80 \%$ coverage of at least one ANC contact with a skilled provider, ${ }^{15} 16$ late initiation of ANC visits, lower health facility births and very low PNC use still pose enormous challenges. A study in The Lancet reported that prevalence of early initiation of ANC contact $(<14$ weeks of gestation) was only $24 \%$ in SSA, much lower compared with $85 \%$ in high-income countries. ${ }^{17}$ The challenge in a number of SSA countries, however, is that despite the removal of user fees for all maternal and child health service in many countries, a number of sociodemographic factors and maternal characteristics still remain critical determinants of care use that hinder or motivate choices and preferences in maternal care seeking. ${ }^{18}$

Andersen and Newman behavioural model of use of healthcare services has widely been used to identify factors that influence care-seeking behaviour. ${ }^{19}$ The model outlines three main factors that interact to predict use of care, and they included societal, individual and health system determinants ${ }^{19}$ (see diagrammatic details in online supplemental file 1). The model has been employed by studies to examine use of the different components of maternal and newborn care such as ANC, ${ }^{20}{ }^{21}$ childbirth $^{22}$ or PNC. ${ }^{23}$ However, very few studies in SSA have assessed how factors in the Andersen and Newman model modify care-seeking behaviour along the continuum of care from pregnancy to postnatal period, and even much fewer within the context of free maternity policy.

A recent community-based study in Ethiopia showed that women with higher education, married women and those with autonomy in healthcare decision were likely to complete continuum of care. ${ }^{24}$ Whereas the study provided critical findings, it considered only one ANC visit and not the WHO or Ministry of Health $(\mathrm{MoH})$ recommended number of contacts. ${ }^{24}$ Another similar study by Oh et al. 2013 in Gambia also found a number of factors associated with maternal care-seeking continuum and early ANC visits. ${ }^{25}$ However, the study lacked PNC estimates for facilities deliveries. ${ }^{25}$ Another subnational study in Tanzania found, among other factors, knowledge or experience of pregnancy danger signs was associated with higher care seeking. ${ }^{26}$ A 2019 Cochrane review of several qualitative studies found that influence by others, illness-free pregnancy, financial dependence and selective use of ANC are potential barriers to continual maternal care use. ${ }^{27}$ The few existing studies on continuum of care seeking in SSA are very informative but limited in one way or another, and none to our knowledge examined associated neonatal survival outcomes.

Kenya and Uganda are among the 10 countries in SSA countries with most neonatal deaths ${ }^{28}$ and despite relatively free or subsidised maternity policy in both countries and relatively higher gross domestic product than some countries in the East Africa region such as Rwanda, neonatal mortality rates have declined much slower compared with Rwanda. ${ }^{29}{ }^{30}$ Thus, this study aimed to examine how sociodemographic and maternal factors influence care-seeking behaviour in the care-seeking continuum from pregnancy, childbirth to postnatal period in Kenya and Uganda. A secondary aim was to estimate the impact of levels of continued maternal care seeking on neonatal survival.

\section{METHODS}

\section{Study settings}

Kenya and Uganda have closely comparable demographics and are in relatively similar state of maternal healthcare policy and pathway towards achieving universal coverage. The total population in Kenya and Uganda as of 2016-2019 was about 90 million. ${ }^{31}{ }^{32}$ More than $70 \%$ of the populations live in the rural areas with agriculture as their main source of livelihood. ${ }^{31} 3334$ The sex ratio is approximately $1: 1,{ }^{31} 35$ and general life expectancy at birth in 2016 was similar in both countries; for women, it was 64 and 67 years in Uganda and Kenya, respectively. ${ }^{36}$ Maternal mean age at first childbirth is 19-20 years. Neonatal mortality rates in both countries were about 22 deaths per 1000 live births in $2016 .{ }^{30}$ Like a number of countries in SSA, Kenya and Uganda provide free maternal care services in primary-level health facilities. ${ }^{37}$ Although the goal of the free maternity programmes in Kenya and Uganda is to eliminate all maternity-related costs, due to inadequate or slow distribution of funding in some health facilities, certain hidden costs such as for ultrasound, access to hospital card and laboratory services among others are still incurred out-of-pocket. ${ }^{38-42}$ Additionally, indirect expenses such as costs of transportation to the health facility are still challenges common among poor households. ${ }^{39}$ Further, in Kenya, prior to June 2013, maternal services were partly free and partly subsidised. ${ }^{43}$

\section{Data source and study design}

We obtained the cross-sectional, populationrepresentative, Demographic and Health Surveys (DHS) datasets for Kenya 2014 and Uganda 2016 after a formal request to the DHS secretariat. DHS collects sociodemographic, maternal and child health data across the whole country in a two-stage cluster sampling procedure. The DHS uses standard procedures and protocols that ensure complete anonymity of the respondents and adherence to international ethical standards for research. We used the data for the most recent live births, 1-59 months prior to the surveys. More details on data collection procedure can be accessed from DHS methodology and manuals. ${ }^{445}$ 
Table 1 Classification of continuum of care-seeking classes during the antenatal period, childbirth and within 28 days of postnatal period in Kenya and Uganda

\begin{tabular}{|c|c|c|c|c|}
\hline & $\begin{array}{l}\geq 4 \text { ANC } \\
\text { visits }\end{array}$ & $\begin{array}{l}\text { 2-3 ANC } \\
\text { visits }\end{array}$ & $\begin{array}{l}1 \text { ANC } \\
\text { visit }\end{array}$ & $\begin{array}{l}0 \text { ANC } \\
\text { visit }\end{array}$ \\
\hline \multicolumn{5}{|c|}{ Health facility births } \\
\hline $\begin{array}{l}\mathrm{PNC}- \\
\text { yes }\end{array}$ & Highest & Higher & $\begin{array}{l}\text { Seventh } \\
\text { lowest }\end{array}$ & - \\
\hline $\begin{array}{l}\mathrm{PNC}- \\
\text { no }\end{array}$ & High & $\begin{array}{l}\text { Moderately } \\
\text { high }\end{array}$ & $\begin{array}{l}\text { Sixth } \\
\text { lowest }\end{array}$ & $\begin{array}{l}\text { Third } \\
\text { lowest }\end{array}$ \\
\hline \multicolumn{5}{|c|}{ Birth outside of health facility } \\
\hline $\begin{array}{l}\mathrm{PNC}- \\
\text { yes }\end{array}$ & Slightly high & $\begin{array}{l}\text { Moderately } \\
\text { lower }\end{array}$ & $\begin{array}{l}\text { Fifth } \\
\text { lowest }\end{array}$ & $\begin{array}{l}\text { Second } \\
\text { lowest }\end{array}$ \\
\hline $\begin{array}{l}\text { PNC- } \\
\text { No }\end{array}$ & $\begin{array}{l}\text { Moderately } \\
\text { low }\end{array}$ & Very low & $\begin{array}{l}\text { Fourth } \\
\text { lowest }\end{array}$ & Lowest \\
\hline
\end{tabular}

ANC, antenatal care; PNC, postnatal care.

\section{Study variables}

\section{Outcome variables}

Care-seeking continuum was the primary outcome variable. It constituted a combination of the number of ANC visits, health facility birth and at least one PNC contact within 28 days postpartum (after birth). Continuum of care seeking was categorised into 15 classes based on relative adherence to basic (modified) $\mathrm{WHO}$ and $\mathrm{MoH}$ recommendations for care attendance from pregnancy to postnatal period prior to 2016, that is, before the current WHO recommendation of 8 ANC visits. Since data for both countries were collected prior to the new WHO 2016 ANC recommendations, we used previous Focused ANC recommendations. A mother with a combination of four or more visits, health facility birth (skilled birth) and at least one PNC contact was classified in the highest category of care seeking, and those with least/no amount of care were categorised as the lowest class. The intermediate categories were classified on the basis of optimal and perceived descending level of care-seeking behaviour as higher, high, moderately high, slightly high, moderately low, moderately lower, very low, seventh lowest, sixth lowest, fifth lowest, fourth lowest, third lowest, second lowest and lowest, as shown in table 1 .

The first component of classification was in accordance with the number of ANC visits a mother had; the second level was on the basis of whether or not a mother delivered at the health facility; and the last part of continuum of care was whether or not a mother had PNC visit within 28 days postpartum.

Neonatal mortality was a secondary outcome variable that was dichotomised into 'yes' (died) and 'no' (lived), depending on whether the neonate lived or not. The predictor variables for this outcome variable were the modified classes of care-seeking continuum discussed previously as the primary outcomes.
Independent variables

These constituted sociodemographic factors and maternal characteristics that were examined across all care-seeking continuum categories of the primary outcome variable. They included variables that the modified Andersen and Newman behavioural model for care use identified as predictors of care-seeking behaviour. ${ }^{19}$ Further, the categorisation of these variables was also informed by a number of maternal and child health studies previously conducted in SSA. They included maternal age, which was initially grouped as 15-19, 20-24, 25-29, 30-34, 35-39, 40-44 and 45-49 years old, and we recategorised it into 15-24, 25-34 and 35-49years years old, while place of residence remained as rural and urban. ${ }^{46}$ Marital status was dichotomised into single or married. ${ }^{47}$ A mother having a problem with longer distance/transportation to nearest health facility was classified as 'yes' if it was a problem and 'no' if it was not. ${ }^{48}$ Desire to have a newborn child, whether or not the mother was told about pregnancy complications ${ }^{49}$ and having exposure to mass media ${ }^{50}$ were all categorised as 'yes' and 'no'. The variable who ultimately makes maternal care-seeking decisions was categorised as respondent (woman) alone, husband alone or joint decision. ${ }^{51}$ Education was categorised as no education, primary education and secondary or higher. ${ }^{52}$ Parity (number of children ever born) was categorised as primiparous (for first time mothers), para 2-3 (for those with two to three children) and para $4+{ }^{46}$ Wealth status was classified into poor (poor/poorest), middle and rich (rich/richest) ${ }^{52} 53$ The wealth status in DHS is indexed based on household cumulative living standards, taking into account assets possessed, water and sanitation facilities. Place of residence was classified into rural and urban. ${ }^{53}$

\section{Mapping the predictor: outcome relationship using directed acyclic graphs (DAGs)}

Prior to the analysis, the DAGs by Textor and colleagues ${ }^{54}$ were used to map the predictors of both care-seeking behaviours and neonatal mortality on the basis of existing peer-reviewed evidence and to identify any confounding bias in our models. Online supplemental file 2, diagrams 1.a and b, illustrate the process. For diagram 1.b, the lower levels of care seeking are represented by a lack of a care component(s) that is/are major non-causal risk factor for neonatal mortality.

\section{Data analysis}

We used cross-tabulations to examine the distribution of mothers across variables and variable categories in the different levels of care-seeking continuum. We also investigated correlations between ANC visits and proportions of health facility childbirths and PNC visits. Multinomial logistic regression models examined the associations between sociodemographic and maternal factors and continued care seeking at different care-seeking classes/ categories, with the lowest class as the reference group. The independent variables were mutually adjusted for each other. 
Binary logistic regression was used to determine the odds ratios (OR) for the associations between the various classes of care-seeking continuum and neonatal mortality. For plausible and valid analysis, nine classes with satisfactory data were used in the overall mortality analysis with the highest class as the reference group. Low birthweight babies and multiple gestations are strong independent risk factors for neonatal death ${ }^{556}$ and thus were excluded in the mortality analysis to obtain adjusted OR $(\mathrm{aOR})$. The rest of the classes were not used owing to fewer numbers in certain neonatal mortality strata. Similarly, countryspecific analysis resulted in elimination of more strata with fewer numbers. Further, the resulting significant aORs were used to estimate attributable risk fraction (AR) and population attributable risk fraction (PAR) for both countries combined. This was to determine proportion of neonatal deaths that would be prevented if mothers in a given lower level of care-seeking continuum had sought care at the highest class. We used Stata V.16 and Microsoft Excel (2021) for analysis and to generate graphical summaries of results. Sampling weights were applied, and we accounted for complex sampling design recommended by the DHS methodology guide. Missing data due to nonresponse were mostly negligible compared with the subpopulation sample sizes and relatively randomly spread across the variable subgroups; they were nevertheless omitted in our analysis. For the variable 'knowledge about pregnancy, birth complications', where data were missing for Uganda, the analysis was only performed for Kenya where plausible.

\section{Estimating attributable neonatal mortality risk proportions associated with low levels of care-seeking continuum} The attributable risk proportions (AR) and population attributable neonatal mortality risk proportion (PAR) were obtain by the formulas $\mathrm{AR}=[(O R 1) / O R)] \times 100$ and $\mathrm{PAR}=\mathrm{Pe} *[(O R 1) / O R)] \times 100$, respectively, where OR is the statistically significant aOR associated with that care-seeking class and $\mathrm{Pe}$ is the proportion of the total mortalities in that given care-seeking class.

\section{Public and patient involvement}

No patients or the public were directly involved in this study.

\section{RESULTS}

Table 2 and figure 1 indicate that over $95 \%$ of mothers had at least one ANC visit, and about $56 \%$ had four or more ANC contacts in Kenya and Uganda. Of those who had four or more ANC visits, $73 \%$ gave birth at a health facility and about $41 \%$ had newborn PNC check-up within 28 days after birth as shown in table 2 .

The scatter plot in figure 2 shows a positive correlation between number of ANC visits and both proportions of facility births and PNC visits. Further, figure 3 shows that a single early ANC visit in the first or second trimester
Table 2 Distribution of mothers by continuum of careseeking classes during the antenatal period, childbirth and within 28 days postnatal in Kenya and Uganda, using Demographic and Health Surveys 2014-2016 data, $\mathrm{N}=24502$

\begin{tabular}{|c|c|c|c|c|}
\hline & $\begin{array}{l}\geq 4 \text { ANC } \\
\text { visits, } \\
n=13888\end{array}$ & $\begin{array}{l}\text { 2-3 ANC } \\
\text { visits, } \\
n=8744\end{array}$ & $\begin{array}{l}1 \text { ANC } \\
\text { visit, } \\
n=775\end{array}$ & $\begin{array}{l}0 \text { ANC } \\
\text { visit, } \\
n=1095\end{array}$ \\
\hline \multicolumn{5}{|c|}{ Health facility births } \\
\hline PNC-yes & $4961(35.7)$ & $2355(26.9)$ & 115 & $68(6.2)$ \\
\hline PNC-no & $5179(37.3)$ & $2782(31.8)$ & 213 & $106(9.6)$ \\
\hline \multicolumn{5}{|c|}{ Birth outside of health facility } \\
\hline PNC-yes & $752(5.4)$ & $632(7.2)$ & 63 & $121(11.1)$ \\
\hline PNC-no & $2996(21.6)$ & $2975(34.0)$ & 384 & $800(73.1)$ \\
\hline
\end{tabular}

increased the likelihood of health facility childbirth as opposed to late ANC visit in the third trimester.

Table 3 shows the distribution of maternal and sociodemographic characteristics by care-seeking behaviour from pregnancy to postnatal period. Majority $(\geq 46 \%)$ of the mothers were between 25 and 34 years of age in all care-seeking categories. Overall, about $71 \%$ of the mothers lived in a rural setting, and $37 \%$ of all women had problems with distance to the nearest health facility. Roughly $30 \%$ and $57 \%$ of those who had the highest and the lowest care-seeking tendencies, respectively, indicated distance could be a hindrance to care seeking. Slightly over half of all the mothers had primary education. About $40 \%$ of the highest careseekers had secondary or higher education, while $60 \%$ of the lowest careseekers had no formal education. Similar trends were observed among their husbands/partners (education).

Table 4 shows the results of the multinomial regressions for the associations between independent factors and different classes of care-seeking continuum from pregnancy to childbirth and 28 days postnatal, with the lowest class being the reference category. Maternal primary or

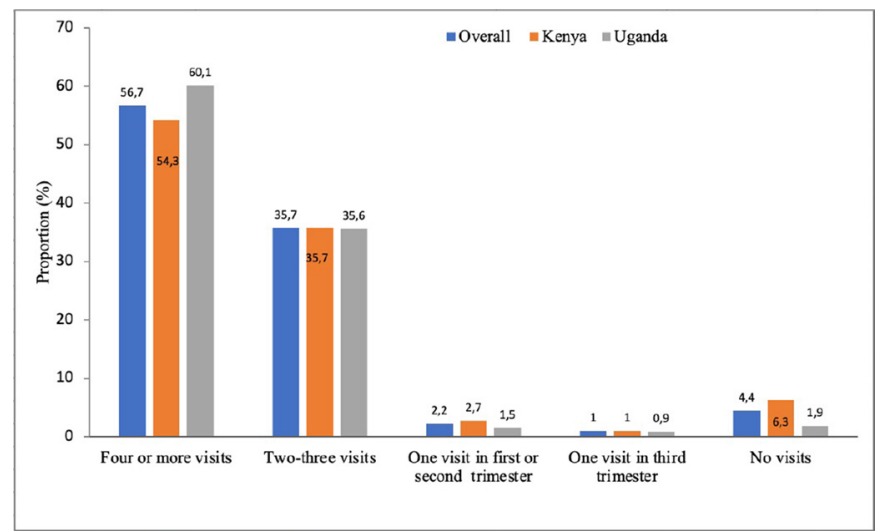

Figure 1 Proportions of antenatal care visits by number of antenatal care contacts in Kenya and Uganda, using Demographic and Health Surveys 2014-2016 data. 


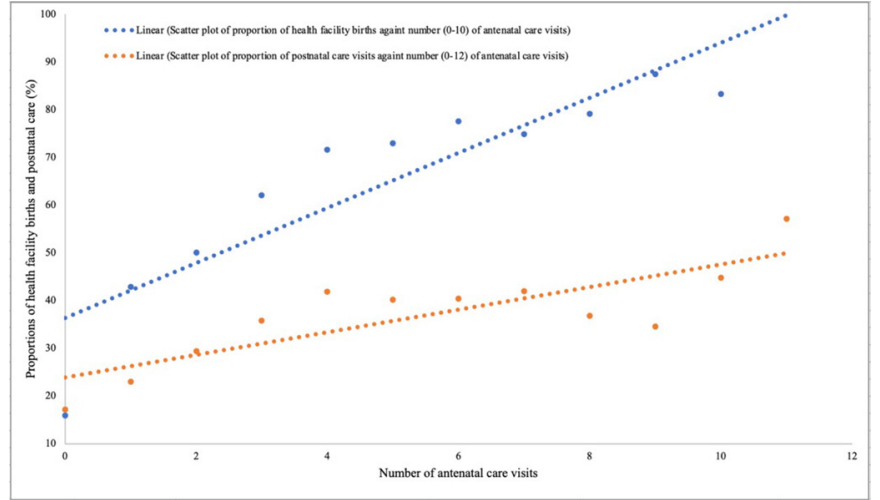

Figure 2 Scatter plot showing correlation between number of antenatal care visits and proportions of facility births and postnatal care visits in Kenya and Uganda, using Demographic and Health Surveys 2014-2016 data.

higher education levels compared with no formal education,were significantly associated with higher care-seeking behaviour in almost all care-seeking categories except among those who had one ANC visit/facility birth/no PNC (sixth lowest) or less; relative risk ratios (RRRs) ranged from 2.1 to 8.0 (95\% CI 1.1 o 16.3). Similarly, trends were observed among those with husbands having primary education and above; RRRs ranged from 2.1 to 6.4 (95\% CI 1.3 to 10.6$)$. Generally, the higher the level of education, the higher the care-seeking tendency. Exposure to mass media (radio/television) was generally associated with higher care-seeking tendency; RRRs ranged from 1.8 to 3.2 (95\% CI 1.2 to 5.4 ). There was minimal indication that desire to have a child improves care seeking, although high RRR to seek care were observed among those who had two or more ANC visits, but findings were not statistically significant except in the high category.

Problem with distance to the health facility (vs no problem) was largely a demotivating factor to care seeking. In six care-seeking categories, the RRRs ranged from 0.6 to 0.7 (95\% CI 0.5 to 0.9 ), whereas in the remaining categories, very low to lowest, the association was marginally

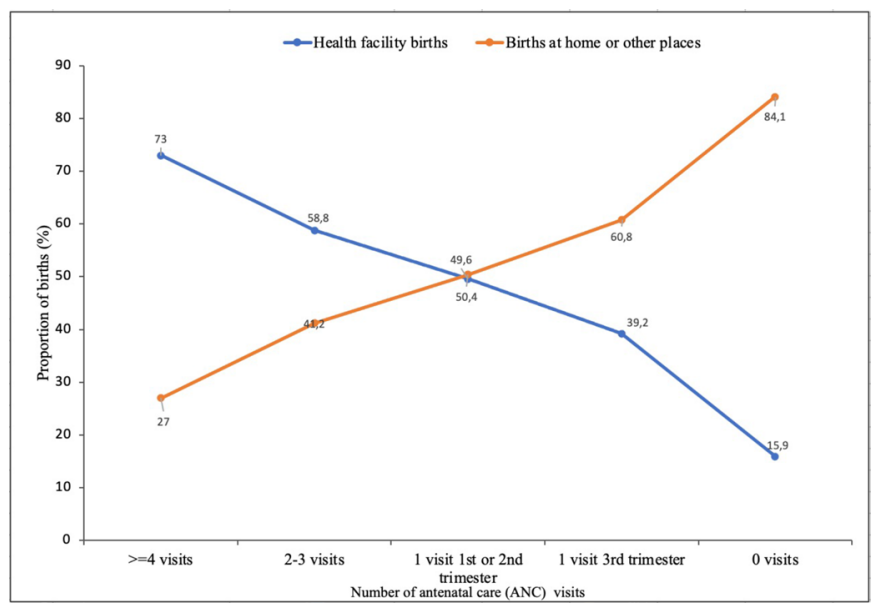

Figure 3 Proportion of hospital and home births by number of antenatal care visits in Kenya and Uganda, using Demographic and Health Surveys 2014-2016 data. not statistically significant; RRRs ranged from 0.6 to 1.1 (95\% CI 0.3 to 1.4 ). Higher parity versus primiparous was not associated with care seeking except in a few careseeking categories among those who had 2-3 ANC visits. Generally, being told about pregnancy and birth complications significantly increased the tendency to seek care in Kenya.

Older maternal age compared with young age was generally not significantly associated with care seeking at all levels of care-seeking continuum, RRRs ranged from 0.4 to 0.9 (95\% CI 0.3 to 1.7 ), except marginally significant in moderately high and seventh lowest classes. Living in a rural area versus urban was significantly associated with lower care-seeking tendency in nine categories. The remaining care-seeking categories indicated lower tendency but not significant results. Care seeking was also notably hindered when the husband/partner rather than the woman made major decisions for maternal care seeking in about nine care-seeking categories. Being married showed variably and inconsistent associations with care seeking in most care-seeking classes, there was no significant association with care-seeking when compared with single mothers. Compared with the poor, the middle wealth status only showed significantly higher care-seeking tendency in the first four higher care-seeking classes and two other random classes; the rest were not statistically significant. Additionally, being rich indicated almost no significant association with care seeking. Figure 4 summarizes in a forest plot the selected (extremes) results from table 4 .

Table 5 presents the ORs for the associations between continued care-seeking categories and neonatal mortality, with the highest category as the reference class. Figure 5 shows a forest plot of aOR for overall results in table 5 . Overall, third lowest and lowest categories were associated with about ourfolds odds of neonatal mortality (aOR 4.2, 95\% CI 1.6 to 10.9). For joint Kenya and Uganda, moderately high and very low levels of care seeking also showed significant higher odds of neonatal death; aOR ranged 1.9-2.4 for the two classes. However, the remaining two categories (fourth lowest and moderately low) did not indicate any statistically significant association with mortality. For Kenya only, lowest, very low, moderately low, moderately high and high versus highest were all significantly associated with neonatal deaths and neonates in the lowest class were six times likely to die. For Uganda, only very low category was significantly associated with neonatal death (aOR 1.7, 95\% CI 1.1 to 2.7), and the lowest class showed higher odds but had a marginally not significant aOR 2.5 (95\% CI 1.0 to 6.0 ). We observe that the proportion of Ugandan mothers seeking continued care at the highest level was more than twice $(33.8 \%)$ that of Kenya $(13.4 \%)$

Still in table 5, in combined country findings, comparing higher and moderately high classes both with two to three ANC visits and facility childbirth, the only difference is lack of PNC attendance in the moderately high class, indicating that lack of PNC contributes significantly to neonatal deaths (aOR 2.2, 95\% CI 1.4 to 3.4). Similarly, in Kenya, $16 \%$ of mothers were in this (moderately high) 


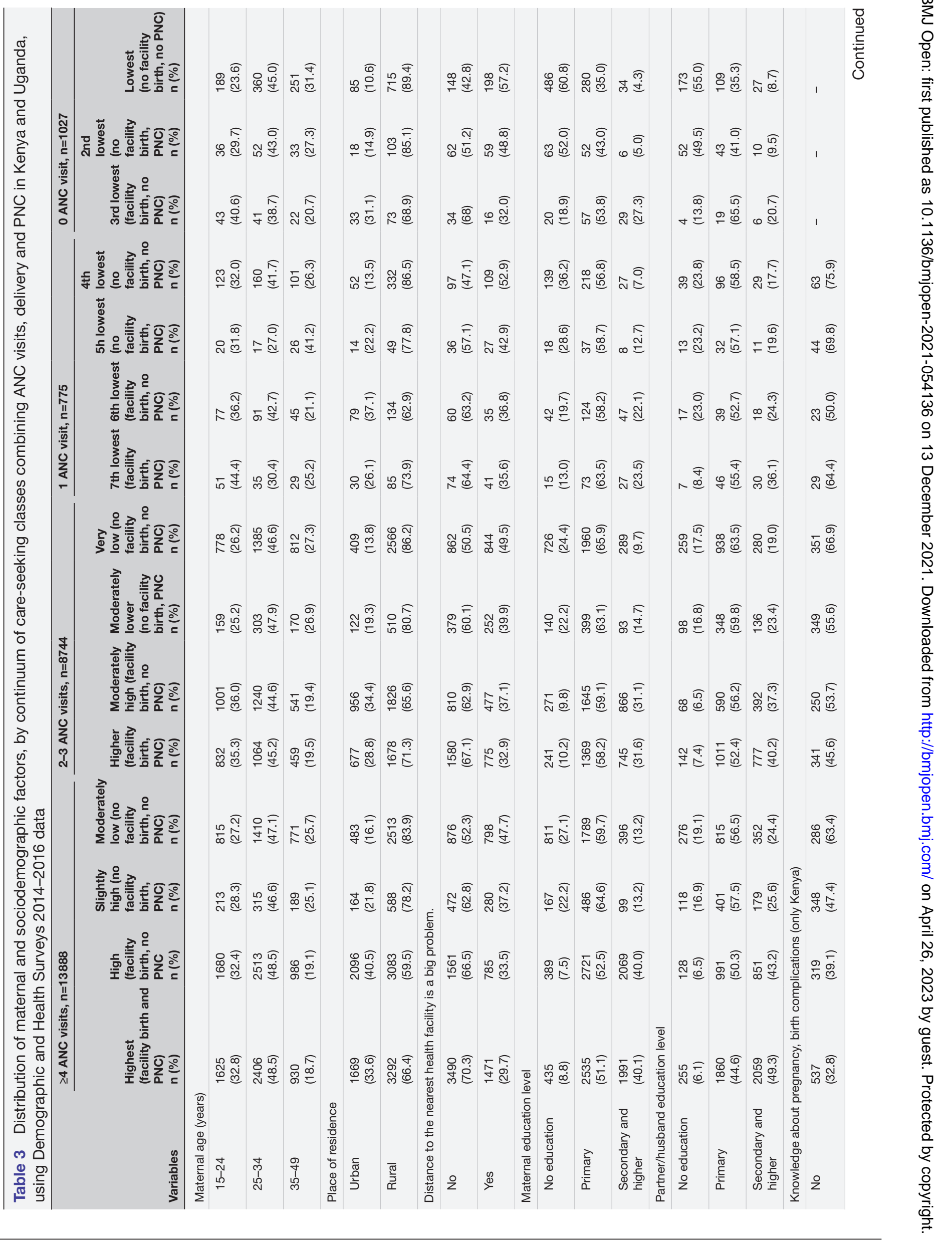




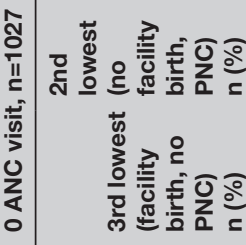

政

ริ)

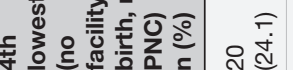

苟

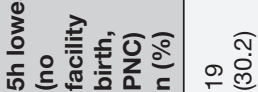

范

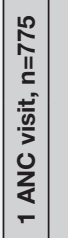

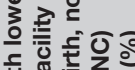

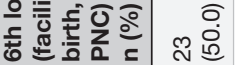

获

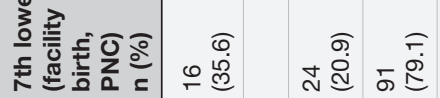

을 $\stackrel{\circ}{\complement}$

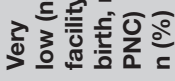

궁

施

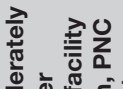

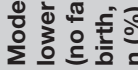

긍

需 要

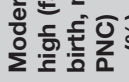

$\div$

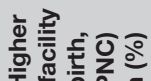

字

政

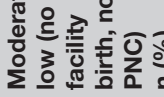

0
0
0
0
0

을 윰

бợ

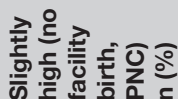

\&)

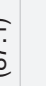

बढ

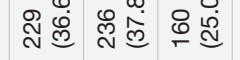

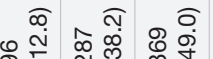

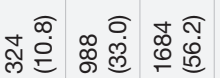

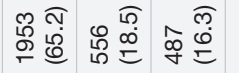

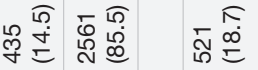

$\geq \stackrel{2}{2}$

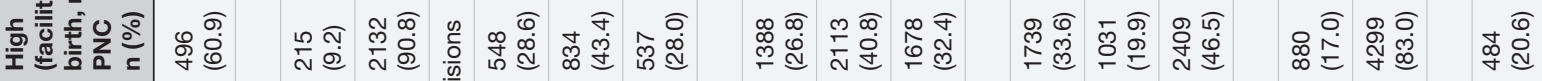

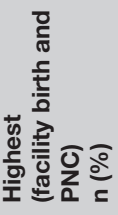

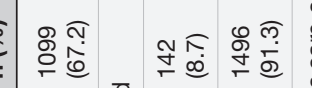

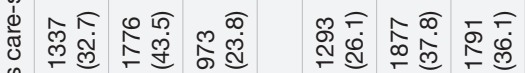

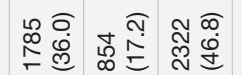

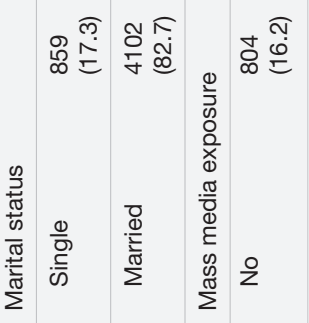




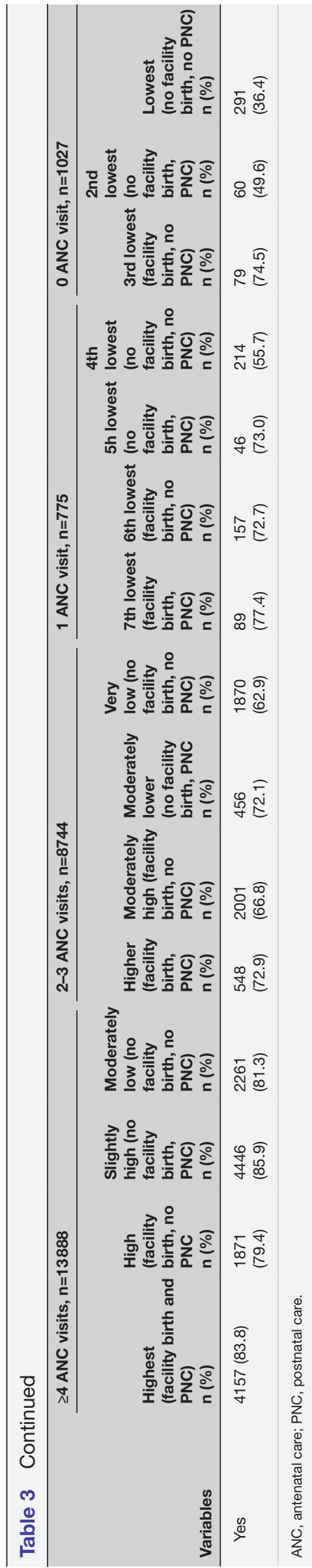

category (aOR 3.4, 95\% CI 1.6 to 7.4). In Uganda, only about $8 \%$ of mothers were in this category. It can generally be observed that care-seeking tendencies are higher in Uganda compared with Kenya, with mothers seeking care at highest level more than doubles that of Kenya $(33.8 \%$ vs $13.4 \%)$. Similarly, at the lowest level, Uganda is more than thrice lower than Kenya ( $1.5 \%$ vs $5.6 \%$ )

Figure 6 shows that, overall, for both Kenya and Uganda, $23 \%$ of neonatal deaths were attributable to inadequate maternal care seeking during pregnancy, childbirth and 28 days postnatal period in Kenya and Uganda. Insufficient care seeking within the lowest and third lowest careseekers accounted for almost three-quarters $(75 \%)$ of neonatal deaths in those groups. About 9\% of neonatal deaths in Kenya and Uganda could be attributable to home births, no PNC visits and inadequate ANC visits.

\section{DISCUSSION}

Although 95\% of mothers initiated the first ANC visit in Kenya and Uganda, only about $20 \%$ completed recommended (modified) care attendance of four or more ANC visits, health facility birth and at least one PNC visit within 28 days after birth. Despite the relatively free or subsidised maternity costs in first level facilities in Uganda and Kenya, several factors still exert profound influence on care-seeking behaviour along the continuum of care that consequently impact neonatal survival. Overall, being educated indicated the highest odds of continual care seeking, and parental education was two to eight times associated with continued care seeking in most of the care-seeking categories. The higher the education level, the higher tendency to seek care. Our results concur with other studies that have shown associations between education and uptake of $\mathrm{ANC},{ }^{57} 58$ institutional birth $^{57} 59$ and PNC. ${ }^{60}$ Further, consistent with our findings, studies have reported higher use of obstetric care among mothers exposed to mass media. ${ }^{61}$ Being told of pregnancy complications also improved care seeking (in Kenya). Over 23\% of neonatal deaths in Kenya and Uganda would be prevented if mothers adhered to recommended care attendance. Desire to have a child, parity and being married did not show any consistent associations with continued care-seeking behaviour. Advance maternal age indicated lower tendency to seek care, but the findings were not statistically significant.

Conversely, a husband as the main or joint decision maker concerning maternal health care seeking was generally a significant demotivating factor to care seeking among the women in Kenya and Uganda. Although our study could not examine this further, other studies have shown that gender inequality, negative sociocultural factors and women's financial marginalisation tend to hinder women's independent decision making in healthcare especially in low-income and middle-income (LMIC) settings. ${ }^{62} 63$ Over $80 \%$ of the mothers in this study were married and over $70 \%$ lived in rural areas, meaning most women are housewives with subsistence farming as 


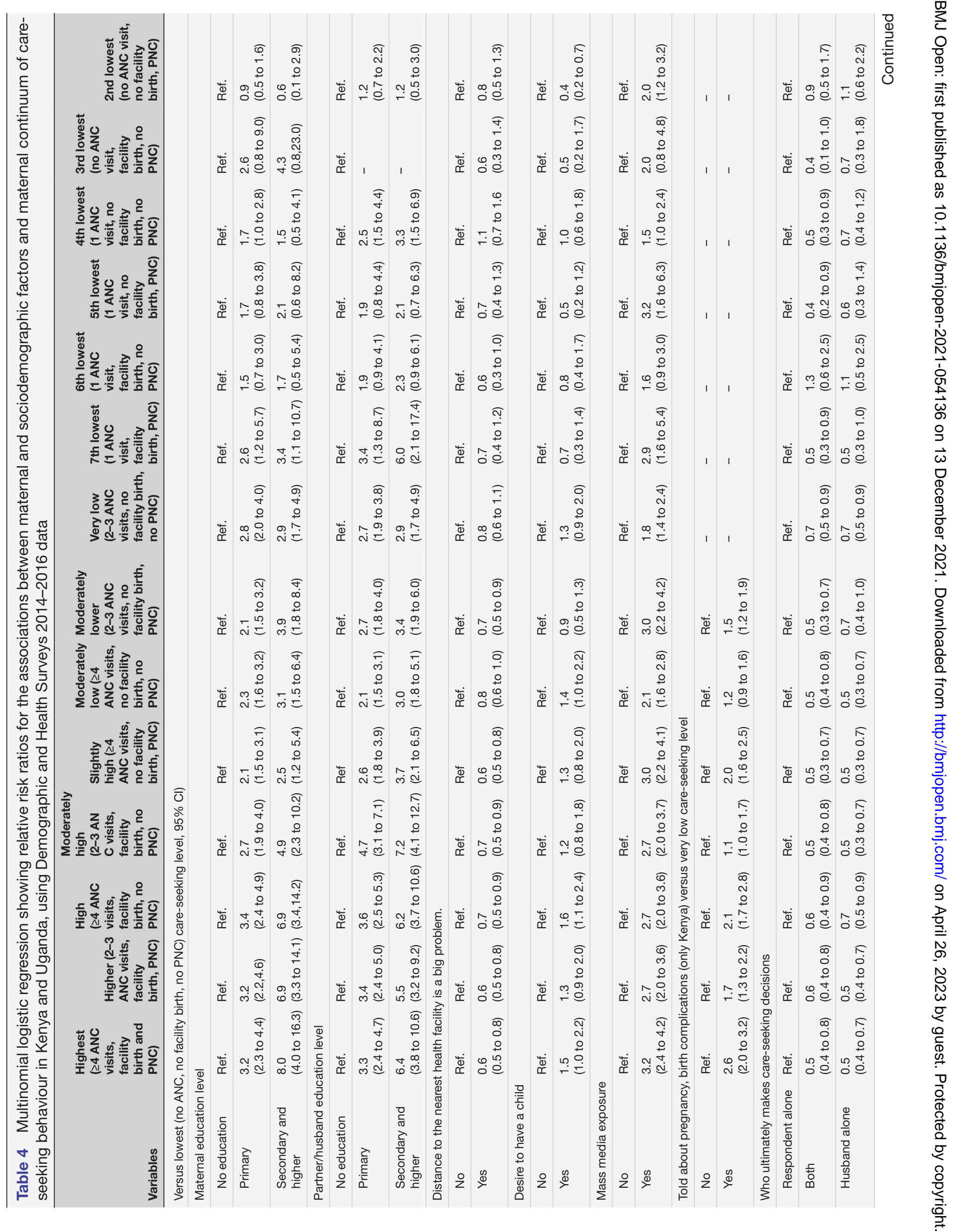




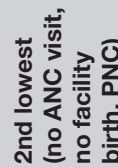

苑

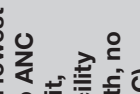

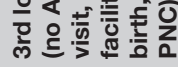

范。일

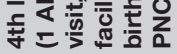

范。方

苛 ᄃ宩西

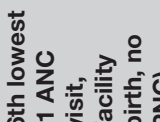

苾势

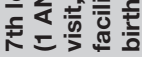

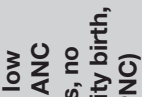

>

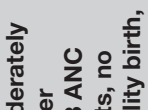

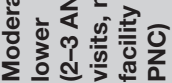

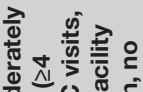

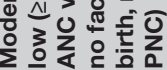

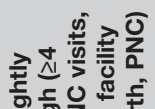

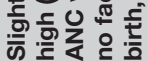

ते

$z$ 通?

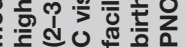

0

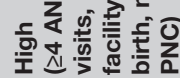

d d

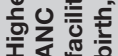

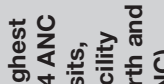

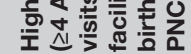

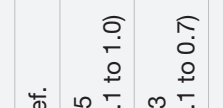

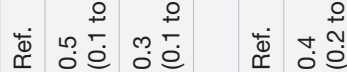

लำ

这

.

巡

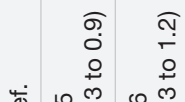

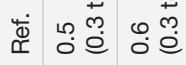

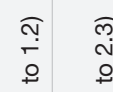

㐫

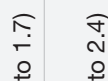

幽

ळ

- 0

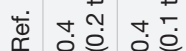



正

离

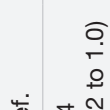

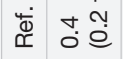

\begin{aligned} 0 \\ \multirow{2}{*}{} \\ 0 \\ 0 \\ 0 \\ 0\end{aligned}

㐫

峁

$\hat{r}$
0
0
0
0
0

㐫

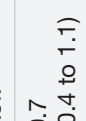

r.

苂

这

๘

茂

$\sigma$
$\dot{0}$
$\dot{0}$

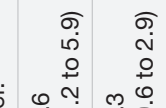

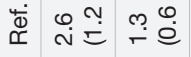

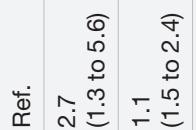

هัष<smiles>C1CC[C@@H]2CCC[C@H]2C1</smiles>

凹ัष

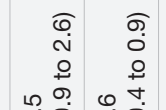

㐫

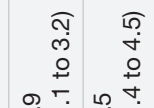

巡
\% 0

这

$\begin{array}{rr}\sigma & 0 \\ 0 & 0 \\ 0 & 0 \\ 0 & 0 \\ 0 & 0 \\ 0 & 0\end{array}$

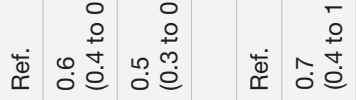

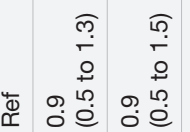

㐫

$\begin{array}{ll}\sigma & 0 \\ 0 & 0 \\ 0 & 0 \\ 0 & 0 \\ 0 & 0 \\ 0 & 0 \\ 0 & 0\end{array}$

苂

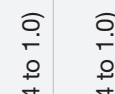

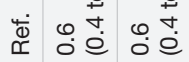

শ্

这 올

T⿱宀

赵

0. 这

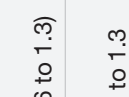

幽 (

$$
\widehat{x}
$$

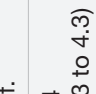

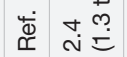

뭄

¿ัष

$r$
$\dot{0}$
0
0
0

这

वे

芉芳莫

宕 r.

命

$+$

远 원

若

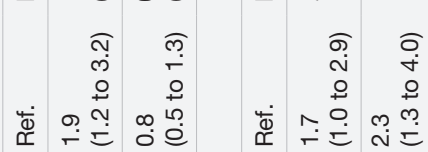

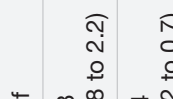

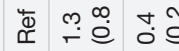

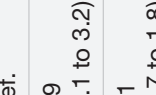

岗

舟送

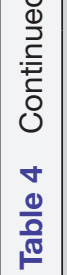

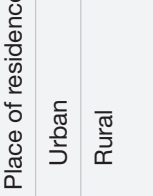

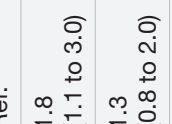

凹ัष 


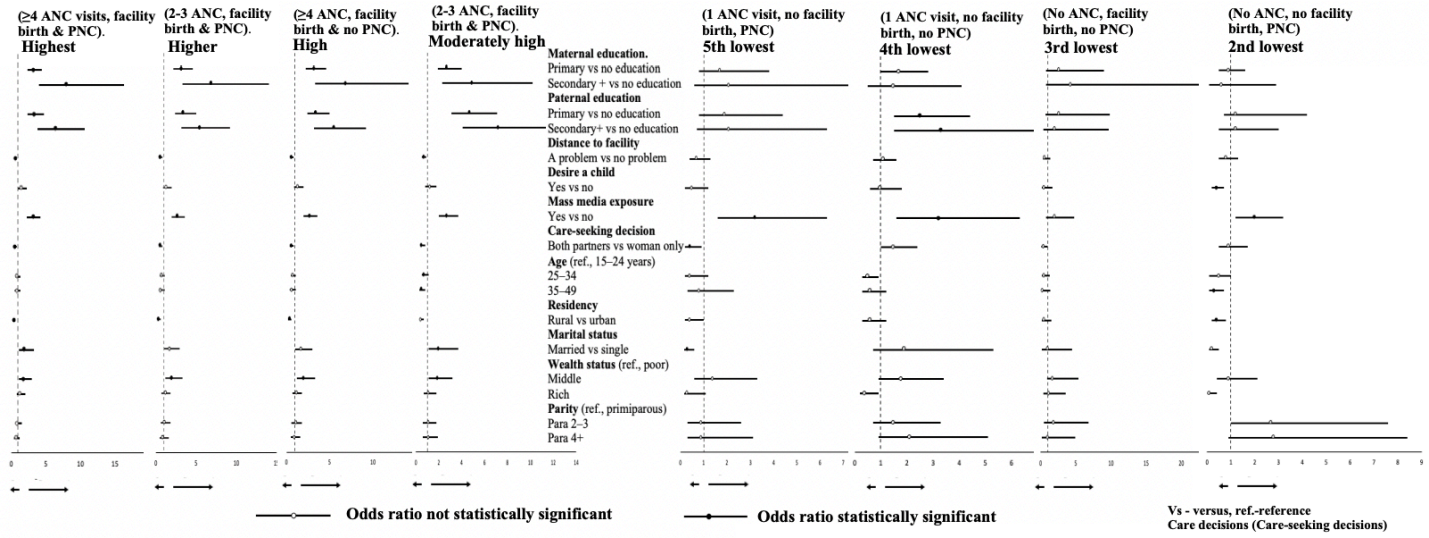

Figure 4 Showing relative risk ratios for the associations between maternal and sociodemographic factors and maternal continuum of care-seeking behaviour in Kenya and Uganda, using Demographic and Health Surveys 2014-2016 data. ANC, antenatal care; PNC, postnatal care.

source of livelihood. Thus, maternal dependency on the husbands to seek care revolves mainly around financial support for repeated transportation and minor hospital expenses, and this can hinder a woman's decision to seek care. This partly explains why being married did not indicate consistent significance to care seeking.
Also, congruent with our findings, a systematic review in Africa by Dahab and Sakellariou reported lack of women autonomy in health decisions as major hindrance to maternity care seeking. ${ }^{64}$ However, a study in Nepal with a similar social setting reported that a complex balance between a woman's independence in maternity decision

Table 5 Crude and aORs for the association between classes of care-seeking behaviour in continuum of care and neonatal mortality in Kenya and Uganda, using Demographic and Health Surveys 2014-2016 data

\begin{tabular}{|c|c|c|c|c|c|c|}
\hline $\begin{array}{l}\text { Classes of care-seeking } \\
\text { behaviour }\end{array}$ & $\begin{array}{l}\text { Overall } \\
\text { crude OR } \\
(95 \% \mathrm{Cl}) \\
\mathrm{n}=22538\end{array}$ & $\begin{array}{l}\text { Overall aOR* } \\
(95 \% \mathrm{Cl})\end{array}$ & $\begin{array}{l}\text { Proportion of the } \\
\text { total in Kenya (\%) } \\
n=12579\end{array}$ & $\begin{array}{l}\text { Kenya only } \\
\text { aOR* } \\
(95 \% \mathrm{Cl})\end{array}$ & $\begin{array}{l}\text { Proportion of } \\
\text { the total in } \\
\text { Uganda } \\
(\%) n=9959\end{array}$ & $\begin{array}{l}\text { Uganda only } \\
\text { aOR* } \\
(95 \% \mathrm{Cl})\end{array}$ \\
\hline $\begin{array}{l}\text { Higher ( } 2-3 \text { ANC visits, } \\
\text { Health facility birth, yes PNC), } \\
\text { mis }=47\end{array}$ & $\begin{array}{l}1.5 \\
(1.0 \text { to } 2.4)\end{array}$ & $\begin{array}{l}1.3 \\
(0.7 \text { to } 2.2)\end{array}$ & 6.1 & $\begin{array}{l}1.4 \\
(0.4 \text { to } 4.2)\end{array}$ & 16.3 & $\begin{array}{l}0.9 \\
(0.5 \text { to } 1.5)\end{array}$ \\
\hline $\begin{array}{l}\text { High ( } \geq 4 \text { ANC visits, health } \\
\text { facility birth, no PNC), mis }=72\end{array}$ & $\begin{array}{l}1.5 \\
(1.0 \text { to } 2.2)\end{array}$ & $\begin{array}{l}1.5 \\
(1.0 \text { to } 2.3)\end{array}$ & 29.8 & $\begin{array}{l}2.9 \\
(1.4 \text { to } 6.0)\end{array}$ & 15.6 & $\begin{array}{l}1.0 \\
(0.6 \text { to } 1.7)\end{array}$ \\
\hline $\begin{array}{l}\text { Moderately high } \\
\text { ( } 2-3 \text { ANC visits, health facility } \\
\text { birth and no PNC), mis=33 }\end{array}$ & $\begin{array}{l}2.4 \\
(1.6 \text { to } 3.7)\end{array}$ & $\begin{array}{l}2.2 \\
(1.4 \text { to } 3.4)\end{array}$ & 16.0 & $\begin{array}{l}3.4 \\
(1.6 \text { to } 7.4)\end{array}$ & 8.4 & $\begin{array}{l}1.6 \\
(0.9 \text { to } 2.7)\end{array}$ \\
\hline $\begin{array}{l}\text { 4th lowest (1 ANC visit, no } \\
\text { health facility births, no PNC), } \\
\text { mis=2 }\end{array}$ & $\begin{array}{l}2.2 \\
\text { (0.7 to } 6.7)\end{array}$ & $\begin{array}{l}2.2 \\
(0.7 \text { to } 7.3)\end{array}$ & 2.1 & - & 1.2 & - \\
\hline $\begin{array}{l}\text { 3rd lowest (no ANC, health } \\
\text { facility births and no PNC), } \\
\text { mis=2 }\end{array}$ & $\begin{array}{l}7.8 \\
(3.5 \text { to } 17.5)\end{array}$ & $\begin{array}{l}4.2 \\
(1.6 \text { to } 10.9)\end{array}$ & 0.5 & - & 0.4 & - \\
\hline $\begin{array}{l}\text { Lowest (no ANC, no facility } \\
\text { births and no PNC), mis }=17\end{array}$ & $\begin{array}{l}4.5 \\
(2.5 \text { to } 7.8)\end{array}$ & $\begin{array}{l}4.2 \\
(2.3 \text { to } 7.8)\end{array}$ & 5.6 & $\begin{array}{l}6.0 \\
(2.6 \text { to } 13.6)\end{array}$ & 1.5 & $\begin{array}{l}2.5 \\
(1.0 \text { to } 6.5)\end{array}$ \\
\hline
\end{tabular}




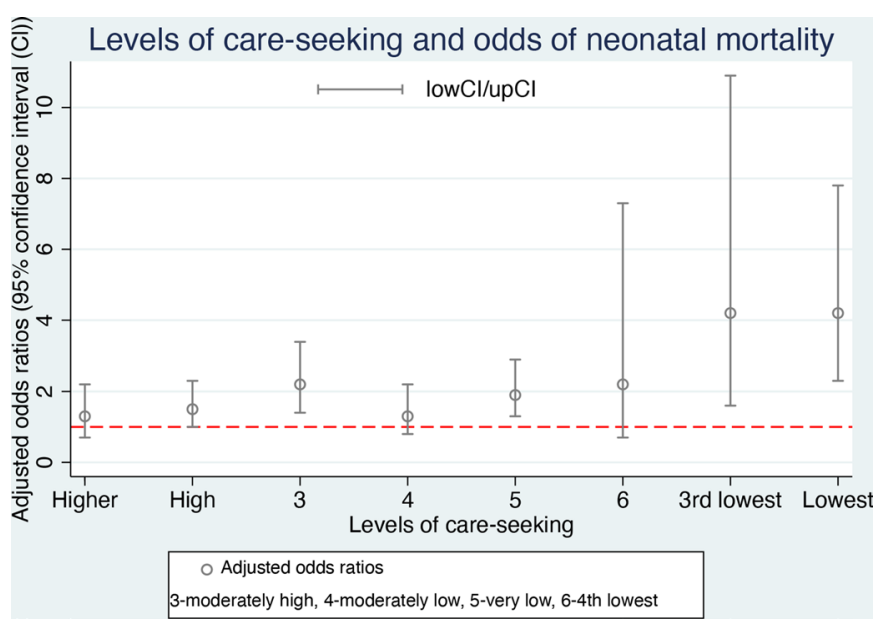

Figure 5 Forest plot showing adjusted ORs between continued care-seeking behavioural classes/levels and neonatal mortality, using Kenya and Uganda, 2014-2016 Demographic and Health Surveys data.

making and the husband's involvement can enhance maternity care seeking. ${ }^{65}$ Living in rural compared with urban areas and longer distance to the nearest health facility largely indicated lower tendency to care seeking; this was especially true (significant) among relatively high care-seeking classes. However, the associations were not statistically significant among mostly lower careseekers. In agreement with most of our findings, two systematic reviews also found longer distance to health facility ${ }^{64}$ and rural residency ${ }^{58}$ as factors that impede care seeking. Being rich did not show any significant association with higher tendency to seek care as would be expected; however, the use of cumulative living standard and assets possessed to determine wealth status does not translate to having liquid cash, readily available to support care seeking. Further research on a valid method to determine wealth status that incorporates monetary availability could be explored.

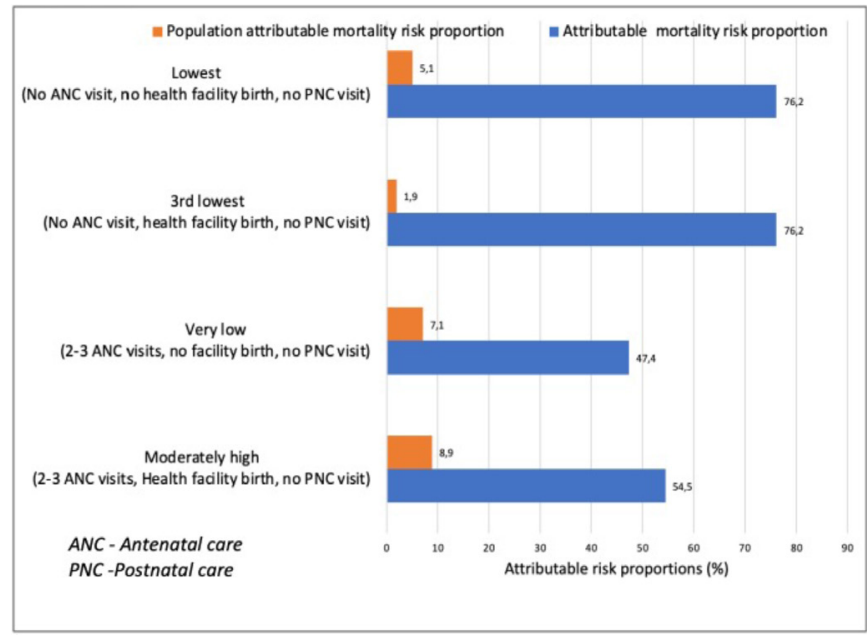

Figure 6 Attributable and population attributable neonatal mortality risk proportion for lower categories of care seeking in Kenya and Uganda, using Demographic and Health Surveys 2014-2016 data.
The far-reaching impacts of maternal and sociodemographic factors on the maternal care-seeking continuum necessitate both short-term and long-term solutions with overarching implications for policy improvements. The 2030 Sustainable Development Goals 4, 5 and 10, which focus on inclusive education and gender equality and reducing inequalities, resonate closely with most of the recommendations emanating from our findings. In the long term, strengthening education for all with purposeful emphasis on maternity care seeking should be integrated into the educational curriculum. A recent systematic review in SSA recommended female education as a strong enabling factor for ANC visits. ${ }^{20}$ Improving knowledge and skills for all will inculcate women-led maternal health decision making and create a supportive social environment that would enhance completion of the care-seeking continuum. In the short term, health promotion for maternal care seeking among pregnant or nursing mothers will improve use and consequently greater neonatal survival.

The positive correlations between ANC and facility birth and PNC found in figure 2 indicate that even the first contact with health personnel can improve continued care use, and these findings concur with other studies. ${ }^{667}$ The third lowest and lowest categories with no ANC, no PNC and only facility birth in the third lowest class accounted for $76 \%$ of within-category neonatal deaths each and a total of $7 \%$ deaths in the total population. Even though these two lowest categories had the highest within-category attributable mortality risks, they contributed relatively lower population attributable deaths partly because there were rather fewer mothers in these categories. In comparison, the mothers in the very low and moderately high categories with two to three ANC visits, no PNC plus facility birth only in the moderately high class accounted for relatively lower within-category deaths each $(50 \%)$; however, they accounted for more neonatal deaths in the Kenya/ Uganda population (16\%) since relatively more mothers were in this category.

Given the findings in figure 5, the results of the first three care-seeking classes (higher, high, and moderately high) and last two classes (third lowest and lowest) seem to corroborate theoretical expectations in the 'hierarchy' of consequences of inadequate care seeking. However, the odds for neonatal mortality in class 4 (moderately low) and class 6 (fourth lowest) were not statistically significant for neonatal deaths as would be expected. Notably, in table 5, the moderately low with $\geq 4$ ANC visits and no facility birth and no PNC showed significant association with neonatal death in Kenya but not in Uganda. A possible explanation would be that the quality of ANC given in Uganda was perhaps better and protective than that in Kenya. We could not deduce any possible explanations from our findings for why the OR in the fourth lowest compared with the highest class was not statistically significance despite the low level of care received.

Further, in table 5, the only difference in care-seeking between higher and moderately high categories (vs highest 
class) is lack of PNC in the latter class. Thus, the statistical significance in the odds for mortality in the moderately high class and not in the higher class reveals that PNC could be very protective and is critical for neonatal survival. Our findings show that PNC is the least attended-to component of care continuum. WHO and other studies also agree that PNC is a crucial phase yet most neglected part of care ${ }^{6869}$ We recommend strategies that enhance PNC use in Kenya and Uganda. One such strategy would be to emphasise PNC right from the first ANC contact, which has not been the case. PNC attendance existed only in the checklists for fourth ANC visit in the focused ANC recommendations in both Kenya and Uganda. ${ }^{70} 71$ This implied that majority of mothers with less than four ANC visits got very limited information that could induce PNC attendance. The current WHO guidelines for eight ANC visits recommend emphasis on continuity of care including PNC; however, it is not clear on how PNC use would be promoted during ANC visits in non-midwife-led continuity of care models such as Kenya and Uganda and other LMIC if it is not clearly specified. ${ }^{72}$ The twice higher proportion of Uganda women in the highest category than Kenya could be attributable to the fact that Uganda's abolition of user fees in 2001 took place much earlier than in Kenya (2013).

Although it was not possible for our study to determine attributable mortality risks for each specific care component, nonetheless, we can deduce that over $23 \%$ of neonatal deaths in Kenya and Uganda could be avoided through basic maternal and newborn care recommendations prior to 2016. We can also reason that if Kenya and Uganda would fully implement the current WHO recommendations of eight ANC visits, it would lead to higher rates of facility births and ensure PNC as indicated in figure 2 , then much higher proportions of neonatal deaths would be eliminated.

For mothers with problems with distance to the nearest health facility, strengthening, structuring and funding the community health workers (CHWs) strategy to engage families, community and health facilities could help align the care-seeking continuum especially for PNC that is currently poorly attended. The village health workers (VHTs) in parts of Uganda, for example, have achieved profound improvement in promoting maternal care seeking. ${ }^{73}$ However, high attrition rate is a major challenge to CHW programmes such as VHTs in Uganda due to poor governmental support. ${ }^{74}$ Given the readily available telephone communication in East Africa, the integration of a mobile health (mHealth) programme specifically for maternal care-seeking in the existing mHealth structure in Kenya ${ }^{75}$ and Uganda ${ }^{76}$ is another viable approach. A cost-free two-way mHealth messaging approach could facilitate follow-up, counter sociodemographic barriers and profoundly improve continued care seeking. Engaging the CHW in this endeavour would be feasible with minimal extra investment.

Studies in Kenya and Uganda reported increased use of ANC and delivery services due to free maternity policy ${ }^{77-79}$ Reports evaluating impacts of free maternity policies in Kenya and Uganda highlight increase of ANC coverage and health facility births, but almost no mention is made of the impact on PNC. ${ }^{40}{ }^{80}$ Other studies have reported that free maternity policy increased mainly facility births. ${ }^{81}{ }^{82}$ The universal health policy in Uganda and the Linda mama strategy ${ }^{83}$ in Kenya advocate for universal access to quality maternity health services but do not offer transportation for poor mothers or health providers in/to remote areas, yet most mothers are rural dwellers. Additionally, there are hidden hospital charges due to underfunding or delayed distribution of funds. 394143

Another worthwhile strategy to improve continued maternity care use among mothers would be to develop a standard questionnaire or a protocol for estimating the level of continued care seeking based on a brief interview of the mother at first ANC visit. The results could be used to determine the degree of follow-up that can be employed to close the care-seeking gap. Such questionnaires have previously been used in to assess health seeking behaviour in sexually transmitted diseases, for example. ${ }^{84}$ It could be based on identified cluster of items including sociodemographic factors that impact careseeking behaviours that after prolonged testing, and validation could be shortened using factor analysis. Previous maternity history of care-seeking continuum could also be used to improve such a standard. Poor care-seeking mothers can then be enrolled in a messaging list or maternity mHealth programme. This can be a less-costly health promotion strategy that could easily be integrated in ANC set-up in low-resource healthcare settings.

\section{Methodological considerations}

The large sample size of the maternal and child data of the latest Kenya and Uganda DHS, which are nationally representative, allowed for valid stratified analysis for deeper understanding of neonatal health and survival. The study is thus externally valid and generalisable in other similar settings. Like many cross-sectional surveys, recall bias may not be completely eliminated from the study. Nonetheless, by selecting the most recent live births for analysis and because childbirth is a special occurrence that mothers may not easily forget within a short period of time, our findings considerably reflect the reality of maternal care and associated neonatal survival in these countries.

A strength to our study was the use of directed acyclic graphs that enabled us to explicitly map the predictoroutcome relationship for well-guided analysis and identification of possible confounders. Our study could not examine other factors such as poor attitude of nurses and lack of information on healthcare services offered, which have been found by both quantitative and qualitative studies to hinder care use in LMIC countries. ${ }^{85} 86$ Another limitation to our study was that inadequate facilities and drugs have also been associated with poor care seeking, but our data did not capture these specific aspects. ${ }^{87}$ In 
addition, the cross-sectional survey design of the DHS dataset does not allow collection of data on quality of care. Our study did not incorporate factors such as intimate partner violence (IPV), which is prevalent in many countries. IPV is known to be associated with poor careseeking behaviour. ${ }^{88}$ Further studies can investigate this.

\section{CONCLUSION}

Further multicountry large-scale population-based research and systematic reviews could enable development and use of a brief standard questionnaire to determine a mother's continued care-seeking level during the first ANC visit and use the information to close the careseeking gaps where it is most needed. This is especially viable in LMIC with limited health workforce. Similar standard questionnaires have been used previously in other areas to assess care-seeking behaviour. ${ }^{89} 90$ The use of mHealth specifically for promoting continued maternal care use up to postnatal can be integrated in the existing structures. Strengthening the existing CHW system to be an integral part of promoting continued maternal care-seeking could enhance care seeking as a stand-alone strategy or as a component of the aforementioned suggested strategies.

Acknowledgements Much appreciation to the Demographic and Health Surveys programme and partners for availing the datasets for this study.

Contributors MOA conceptualised, designed, obtained data for the study, conducted the analysis, interpreted the results, and drafted and reviewed the manuscript. BOA and AA interpreted the results and conducted a critical review of the manuscript. All authors read and approved final draft. MOA assumes full responsibility for the work.

Funding The authors have not declared a specific grant for this research from any funding agency in the public, commercial or not-for-profit sectors.

Competing interests None declared.

Patient consent for publication Not applicable.

Ethics approval DHS data collection process and storage guaranteed the anonymity and confidentiality of participants. Datasets are publicly available and permission for access and use was obtained after sending the request to the Demographic and Health Surveys secretariat.

Provenance and peer review Not commissioned; externally peer reviewed.

Data availability statement Data are available upon reasonable request. https:// dhsprogram.com/data/available-datasets.cfm.

Supplemental material This content has been supplied by the author(s). It has not been vetted by BMJ Publishing Group Limited (BMJ) and may not have been peer-reviewed. Any opinions or recommendations discussed are solely those of the author(s) and are not endorsed by BMJ. BMJ disclaims all liability and responsibility arising from any reliance placed on the content. Where the content includes any translated material, BMJ does not warrant the accuracy and reliability of the translations (including but not limited to local regulations, clinical guidelines, terminology, drug names and drug dosages), and is not responsible for any error and/or omissions arising from translation and adaptation or otherwise.

Open access This is an open access article distributed in accordance with the Creative Commons Attribution Non Commercial (CC BY-NC 4.0) license, which permits others to distribute, remix, adapt, build upon this work non-commercially, and license their derivative works on different terms, provided the original work is properly cited, appropriate credit is given, any changes made indicated, and the use is non-commercial. See: http://creativecommons.org/licenses/by-nc/4.0/.

\section{ORCID iDs}

Malachi Ochieng Arunda http://orcid.org/0000-0001-8305-0860
Benedict Oppong Asamoah http://orcid.org/0000-0001-7308-1698

\section{REFERENCES}

1 United Nations Inter-Agency Child Mortality Estimation. Levels and trends in child mortality, 2020. Available: https://www.unicef. org/media/79371/file/UN-IGME-child-mortality-report-2020.pdf [Accessed Jan 2021].

2 UNICEF. Neonatal Mortality. Neonatal period is the most vulnerable time for a child [Internet], 2020. Available: https://data.unicef.org/ topic/child-survival/neonatal-mortality/ [Accessed Jan 2021].

3 World Health Organization. Newborn death and illness, 2011. Available: https://www.who.int/pmnch/media/press_materials/fs/fs_ newborndealth_illness/en/

4 World Health Organization. Newborn death and illness, 2005. Available: https://www.who.int/pmnch/media/press_materials/fs/fs_ newborndealth illness/en/ [Accessed Jan 2021].

5 World Health Organization. Newborns: improving survival and wellbeing: key facts, 2021. Available: https://www.who.int/news-room/ fact-sheets/detail/newborns-reducing-mortality [Accessed Jan 2021]

6 World Health Organization. Positive experiences, key to antenatal care uptake and quality, 2019. Available: https://www.who.int/ reproductivehealth/antenatal-care-uptake/en/ [Accessed Jan 2021].

7 World Health Organization. Newborns: improving survival and wellbeing, 2020. Available: https://www.who.int/news-room/fact-sheets/ detail/newborns-reducing-mortality [Accessed Jan 2021].

8 Swedish Public Health Agency (Folkhälsomyndigheten). Infant mortality (Spädbarnsdödlighet), 2019. Available: https://www. folkhalsomyndigheten.se/folkhalsorapportering-statistik/ tolkad-rapportering/folkhalsans-utveckling/resultat/halsa/ spadbarnsdodlighet/ [Accessed Jan 2021].

9 UN IGME. Levels and trends in child mortality report 2019. estimates developed by the un Inter-agency group for child mortality estimation, 2019.

10 Tessema ZT, Yazachew L, Tesema GA, et al. Determinants of postnatal care utilization in sub-Saharan Africa: a meta and multilevel analysis of data from 36 sub-Saharan countries. Ital J Pediatr 2020;46:175.

11 Tran TK, Nguyen CTK, Nguyen HD, et al. Urban - rural disparities in antenatal care utilization: a study of two cohorts of pregnant women in Vietnam. BMC Health Serv Res 2011;11:120.

12 Doctor HV, Nkhana-Salimu S, Abdulsalam-Anibilowo M. Health facility delivery in sub-Saharan Africa: successes, challenges, and implications for the 2030 development agenda. BMC Public Health 2018;18:765

13 World Health Organization. Make every mother and child count. Geneva, Switzerland, 2005.

14 Kerber KJ, de Graft-Johnson JE, Bhutta ZA, et al. Continuum of care for maternal, newborn, and child health: from slogan to service delivery. Lancet 2007;370:1358-69.

15 Benova L, Dennis ML, Lange IL, et al. Two decades of antenatal and delivery care in Uganda: a cross-sectional study using demographic and health surveys. BMC Health Serv Res 2018;18:758.

16 Kichamu GAJ, Karimurio L. Maternal and child health: demographic and health survey.

17 Moller A-B, Petzold M, Chou D, et al. Early antenatal care visit: a systematic analysis of regional and global levels and trends of coverage from 1990 to 2013. Lancet Glob Health 2017;5:e977-83.

18 Gilson L, Mclntyre D. Removing user fees for primary care in Africa: the need for careful action. BMJ 2005;331:762-5.

19 Andersen R, Newman JF. Societal and individual determinants of medical care utilization in the United States. Milbank Mem Fund Q Health Soc 1973;51:95-124.

20 Okedo-Alex IN, Akamike IC, Ezeanosike OB, et al. Determinants of antenatal care utilisation in sub-Saharan Africa: a systematic review. BMJ Open 2019;9:e031890.

21 Neupane B, Rijal S, G C S, et al. Andersen's model on determining the factors associated with antenatal care services in Nepal: an evidence-based analysis of Nepal demographic and health survey 2016. BMC Pregnancy Childbirth 2020;20:308.

22 Jadoon B, Mahaini R, Gholbzouri K. Determinants of over and underuse of caesarean births in the eastern Mediterranean region: an updated review. East Mediterr Health J 2019;25:837-46.

$23 \mathrm{Gu} \mathrm{H}$, You H, Yan Z, et al. Determinants of the utilization of postpartum family visits: evidence from rural areas of eastern China. PLoS One 2018;13:e0194061.

24 Shitie A, Assefa N, Dhressa M, et al. Completion and factors associated with maternity continuum of care among mothers who gave birth in the last one year in Enemay district, Northwest Ethiopia. J Pregnancy 2020;2020:1-9. 
25 Oh J, Moon J, Choi JW, et al. Factors associated with the continuum of care for maternal, newborn and child health in the Gambia: a cross-sectional study using demographic and health survey 2013. BMJ Open 2020;10:e036516.

26 Mohan D, LeFevre AE, George A, et al. Analysis of dropout across the continuum of maternal health care in Tanzania: findings from a cross-sectional household survey. Health Policy Plan 2017;32:791-9.

27 Downe S, Finlayson K, Tunçalp Özge, et al. Provision and uptake of routine antenatal services: a qualitative evidence synthesis. Cochrane Database Syst Rev 2019;6:Cd012392.

28 World Health Organization. Africa's newborns-counting them and making them count. Available: https://www.who.int/pmnch/media/ publications/aonsection_I.pdf [Accessed Jan 2021].

29 Masaba BB, Mmusi-Phetoe RM. Neonatal survival in SubSahara: a review of Kenya and South Africa. J Multidiscip Healthc 2020;13:709-16.

30 The World Bank. Open Data, indicators, neonatal (per 1000 live births)-Kenya, Uganda, Rwanda. 1994-2019, 2021. Available: https:// data. worldbank.org/indicator/SH.DYN.NMRT?locations=KE-UG-RW [Accessed Jan 2021].

31 Kenya National Bureau of Statistics. 2019 Kenya population and housing census.: distribution of population by socio-economic characteristics, 2019.

32 Uganda Bureau of Statistics (UBOS). 2020 statistics Abstract, 2020.

33 Uganda National Web Portal. Agriculture, 2021. Available: https:// www.gou.go.ug/content/agriculture [Accessed Jan 2021].

34 The World Bank. Open data source: agriculture and rural development, 2021. Available: https://data.worldbank.org/topic/ agriculture-and-rural-development?locations=KE-UG [Accessed Jan 2021].

35 Uganda Bureau of Statistics (UBOS). Population and census, 2020. Available: https://www.ubos.org/explore-statistics/20/ [Accessed Jan 2021].

36 The World Bank. Open data source: Life expectancy at birth, females - Kenya, Uganda, 2021. Available: https://data.worldbank. org/indicator/SP.DYN.LE00.FE.IN?locations=KE-UG [Accessed Jan 2021]

37 Leone T, Cetorelli V, Neal S, et al. Financial accessibility and user fee reforms for maternal healthcare in five sub-Saharan countries: a quasi-experimental analysis. BMJ Open 2016;6:e009692.

38 Ministry of health. Situation analysis of newborn health in Uganda: current status and opportunities to improve care and survival. Kampala: Government of Uganda. Save the Children, UNICEF,WHO, 2008.

39 Masaba BB, Mmusi-Phetoe RM. Free maternal health care policy in Kenya; level of utilization and barriers. Int J Afr Nurs Sci 2020;13:100234.

40 Odokonyero TMF, Adong A, et al. Universal health coverage in Uganda: the critical health infrastructure, healthcare coverage and equity 2017.

41 Ministry of health. Linda Mama programme positioning Kenya on the pathway to UHC, health PS.

42 Ross AB, DeStigter KK, Rielly M, et al. A low-cost ultrasound program leads to increased antenatal clinic visits and attended deliveries at a health care clinic in rural Uganda. PLoS One 2013;8:e78450.

43 Kenya National Commission on Human rights. Implementing free maternal health care in Kenya, 2013.

44 Croft TA, Allen, K MJ, et al. Guide to DHS statistics. Rockville Maryland, USA: ICF, 2018.

45 ICF International. Demographic and health survey: Interviewer's manual. Rockville, Maryland, 2019.

46 Asamoah BO, Agardh A, Cromley EK. Spatial analysis of skilled birth attendant utilization in Ghana. Glob J Health Sci 2014;6:117-27.

47 Sandberg J, Odberg Pettersson K, Asp G, et al. Inadequate knowledge of neonatal danger signs among recently delivered women in southwestern rural Uganda: a community survey. PLoS One 2014;9:e97253.

48 Fisseha G, Berhane $\mathrm{Y}$, Worku A, et al. Distance from health facility and mothers' perception of quality related to skilled delivery service utilization in northern Ethiopia. Int J Womens Health 2017;9:749-56.

49 Mwilike B, Nalwadda G, Kagawa M, et al. Knowledge of danger signs during pregnancy and subsequent healthcare seeking actions among women in urban Tanzania: a cross-sectional study. BMC Pregnancy Childbirth 2018;18:4

50 Asp G, Odberg Pettersson K, Sandberg J, et al. Associations between mass media exposure and birth preparedness among women in southwestern Uganda: a community-based survey. Glob Health Action 2014;7:22904.

51 Ahinkorah BO, Budu E, Seidu A-A, et al. Barriers to healthcare access and healthcare seeking for childhood illnesses among childbearing women in sub-Saharan Africa: a multilevel modelling of demographic and health surveys. PLoS One 2021;16:e0244395.

52 Adedokun ST, Yaya S. Factors influencing mothers' health care seeking behaviour for their children: evidence from 31 countries in sub-Saharan Africa. BMC Health Serv Res 2020;20:842.

53 Chakraborty NM, Fry K, Behl R, et al. Simplified asset indices to measure wealth and equity in health programs: a reliability and validity analysis using survey data from 16 countries. Glob Health Sci Pract 2016;4:141-54.

54 Textor J, van der Zander B, Gilthorpe MS, et al. Robust causal inference using directed acyclic graphs: the R package 'dagitty'. Int $J$ Epidemiol 2016;45:1887-94.

55 Vilanova CS, Hirakata VN, de Souza Buriol VC, et al. The relationship between the different low birth weight strata of newborns with infant mortality and the influence of the main health determinants in the extreme South of Brazil. Popul Health Metr 2019;17:15.

56 Magee BD. Role of multiple births in very low birth weight and infant mortality. J Reprod Med 2004;49:812-6.

57 Enos JY, Amoako RD, Doku IK. Utilization, predictors and gaps in the continuum of care for maternal and newborn health in Ghana. Int $J$ MCH AIDS 2021;10:43-53.

58 Tekelab T, Chojenta C, Smith R, et al. Factors affecting utilization of antenatal care in Ethiopia: a systematic review and meta-analysis. PLoS One 2019;14:e0214848.

59 Nigusie A, Azale T, Yitayal M. Institutional delivery service utilization and associated factors in Ethiopia: a systematic review and metaanalysis. BMC Pregnancy Childbirth 2020;20:364.

60 Tolera H, Gebre-Egziabher T, Kloos H. Risk factors for women's non-utilization of decentralized primary health care facilities for postnatal care in rural Western Ethiopia. Ther Adv Reprod Health 2020;14:2633494120928340.

61 Acharya D, Khanal V, Singh JK, et al. Impact of mass media on the utilization of antenatal care services among women of rural community in Nepal. BMC Res Notes 2015;8:345.

62 Sumankuuro J, Crockett J, Wang S. Sociocultural barriers to maternity services delivery: a qualitative meta-synthesis of the literature. Public Health 2018;157:77-85.

63 Ganle JK, Obeng B, Segbefia AY, et al. How intra-familial decisionmaking affects women's access to, and use of maternal healthcare services in Ghana: a qualitative study. BMC Pregnancy Childbirth 2015;15:173.

64 Dahab R, Sakellariou D. Barriers to accessing maternal care in low income countries in Africa: a systematic review. Int $J$ Environ Res Public Health 2020;17:4292.

65 Thapa DK, Niehof A. Women's autonomy and husbands' involvement in maternal health care in Nepal. Soc Sci Med 2013;93:1-10.

66 Fekadu GA, Kassa GM, Berhe AK, et al. The effect of antenatal care on use of institutional delivery service and postnatal care in Ethiopia: a systematic review and meta-analysis. BMC Health Serv Res 2018; $18: 577$

67 Atuhaire R, Atuhaire LK, Wamala R, et al. Interrelationships between early antenatal care, health facility delivery and early postnatal care among women in Uganda: a structural equation analysis. Glob Health Action 2020;13:1830463.

68 Tiruneh GT, Worku A, Berhane Y, et al. Determinants of postnatal care utilization in Ethiopia: a multilevel analysis. BMC Pregnancy Childbirth 2020;20:549.

69 World Health Organization. Who recommendations on postnatal care of the mother and newborn. Geneva, Switzerland: World health Organization, 2014.

70 Ministry of health. Essential maternal and newborn clinical care guidelines for Uganda, 2016.

71 Services MoPHaSaMoM. National guidelines for quality obstetrics and perinatal care.

72 World Health Organization. Who recommendatons on antenatal for a positive pregnancy experience, 2016.

73 Fund UNC. Village health teams, key structures in saving mothers and their babies from preventable deaths, 2018. Available: https:// www.unicef.org/uganda/stories/village-health-teams-key-structuressaving-mothers-and-their-babies-preventable-deaths [Accessed Jan 2021]

74 Agarwal S, Abuya T, Kintu R, et al. Understanding community health worker incentive preferences in Uganda using a discrete choice experiment. J Glob Health 2021;11:07005.

75 Kenya Moh. Kenya standards and guidelines for mHealth systems, 2017-

76 Kamulegeya LH, Ssebwana J, Abigaba W, et al, eds. Mobile Health in Uganda: A Case Study of the Medical Concierge Group, 2019.

77 Lang'at E, Mwanri L, Temmerman M. Effects of implementing free maternity service policy in Kenya: an interrupted time series analysis. BMC Health Serv Res 2019;19:645. 
78 Atuoye KN, Barnes E, Lee M, et al. Maternal health services utilisation among primigravidas in Uganda: what did the MDGs deliver? Global Health 2020;16:40.

79 Njuguna J, Kamau N, Muruka C. Impact of free delivery policy on utilization of maternal health services in County referral hospitals in Kenya. BMC Health Serv Res 2017;17:429.

80 Abuya TDM, Amanda D, et al. Impacts of removing user fees for maternal health services on universal health coverage in Kenya, 2018.

81 Tama E, Molyneux S, Waweru E, et al. Examining the implementation of the free maternity services policy in Kenya: a mixed methods process evaluation. Int J Health Policy Manag 2018;7:603-13.

82 Gitobu CM, Gichangi PB, Mwanda WO. The effect of Kenya's free maternal health care policy on the utilization of health facility delivery services and maternal and neonatal mortality in public health facilities. BMC Pregnancy Childbirth 2018;18:77.

83 Ministry of Health Kenya. Linda Mama programme positioning Kenya on the pathway to UHC, health PS, 2020.

84 World Health Organization. A rapid assessment of health seeking behaviour in relation to sexually transmitted disease, 1995.

85 Nachinab GT-E, Adjei CA, Ziba FA, et al. Exploring the determinants of antenatal care services uptake: a qualitative study among women in a rural community in northern Ghana. $J$ Pregnancy 2019;2019:3532749.

86 Kyei-Nimakoh M, Carolan-Olah M, McCann TV. Access barriers to obstetric care at health facilities in sub-Saharan Africa-a systematic review. Syst Rev 2017;6:110.

87 Xu K, Evans DB, Kadama P, et al. Understanding the impact of eliminating user fees: utilization and catastrophic health expenditures in Uganda. Soc Sci Med 2006;62:866-76.

88 Musa A, Chojenta C, Geleto A, et al. The associations between intimate partner violence and maternal health care service utilization: a systematic review and meta-analysis. BMC Womens Health 2019;19:36

89 Stack RJ, Mallen CD, Deighton C, et al. The development and initial validation of a questionnaire to measure help-seeking behaviour in patients with new onset rheumatoid arthritis. Health Expect 2015;18:2340-55.

90 World Health Organization. Draft protocol. A rapid assessment of health seeking behaviour in relation to sexually transmitted disease, 1995. 